\title{
ASSESSMENT OF CLIENTS' SATISFACTION WITH HEALTH SERVICE DELIVERIES AT JIMMA UNIVERSITY SPECIALIZED HOSPITAL
}

\author{
FEKADU ASSEFA $^{* 1}$, Andualem Mosse ${ }^{2}$, Yohannes H/Michael ${ }^{1}$
}

\begin{abstract}
BACKGROUND: Client satisfaction is considered as one of the desired outcomes of health care and it is directly related with utilization of health services. Nonetheless, there is no adequate information on users' perception about the service provided in the hospital after the implementation of Business process re-engineering reform. Hence, the objective of this study was to assess the perceived levels of clients' satisfaction with health services rendered at Jimma University Specialized Hospital.

METHODS: A cross sectional study was conducted from March 1-8, 2010 on a sample of 422 service users of the hospital using systematic random sampling technique. Data was collected using structured questionnaire and analyzed by SPSS for windows version 16.0. Statistical tests were employed where necessary at 0.05 level of significance.

RESULT: The questionnaire was administered to a total of 422 clients, of which, $51.7 \%$ were male, about 33.4\% of the respondents were between the age group $25-34,41 . \%$ of the clients were illiterates, $60 \%$ were from the rural areas and $57.8 \%$ received the service free of charge. The findings of the study showed that the overall client satisfaction level with the health services rendered at the hospital was $77 \%$. Satisfaction was reported to be highest (82.7\%) with the way the doctors examined them and on the other hand dissatisfaction was reported to be highest (46.9\%) by respondents with the time spent to see a doctor. Furthermore, satisfaction with the health care was found to have a significant association with the age of the respondents $(p=0.034)$ and educational level of the respondents $(p=0.003)$.

CONCLUSION: This study showed higher clients' satisfaction level in the University Specialized Hospital when compared to previous studies in the same hospital as well as other similar studies in the country. Lack of drugs and supplies, poor information provision, long waiting time, poor cleanliness, lack of privacy and inadequate visiting hours, were found to be the major causes of dissatisfaction. Therefore, the Hospital management should understand these weak service areas and plan for a better service delivery.

KEYWORDS: Hospital, Outpatient Department, inpatient, satisfaction.
\end{abstract}

\section{INTRODUCTION}

Client satisfaction is the level of satisfaction that clients experience having used a service. It therefore reflects the gap between the expected service and the experience of the service, from the client's point of view. Measuring client or patient satisfaction has become an integral part of hospital/clinic management strategies across the globe. Moreover, the quality assurance and accreditation process in most countries requires that the satisfaction of clients be measured on a regular basis (1).

\footnotetext{
${ }^{1}$ Department of health services management, College of Public Health and Medical Sciences, Jimma University ${ }^{*}$ Corresponding author: E-mail: fekadujiru@yahoo.com

${ }^{2}$ Department of Biomedical Sciences, College of public health and medical sciences, Jimma University, Email:andualemm2000@gmail.com
} 
Asking patients what they think about the care and treatment they have received is an important step towards improving the quality of care, and ensure local health services are meeting patients' needs (2). It is an established fact that satisfaction influences whether a person seeks medical advice, complies with treatment and maintains a continuing relationship with practitioners $(3,4)$. Donabadian, arguably the leading theorist in the area of quality assurance, has emphasized that Client satisfaction is of fundamental importance as a measure of the quality of care because it gives information on the provider's success at meeting those client values and expectations, which are matters on which the client is the ultimate authority $(5,6)$.

In the prior years when hospitals were symbols of humanitarian efforts for community welfare, accountability for performance was of little concern. Today however, people are increasingly concerned about hospital's performance because: -1) Hospitals use an increasing proportion of scarce community resources. 2) There are increasing questions about quality and effectiveness. (9). Moreover, addressing those service aspects of healthcare that consumers most readily appreciate, such as access, provider relationship, availability of information and opportunity for participation can influence health care quality outcomes $(7,8)$.

A recent study from Bangladesh reported that the most powerful predictor for client satisfaction with health services was provider behavior, especially respect and politeness (9).

It is indicated that health care systems in most developing countries suffer from serious deficiencies in financing, efficiency, equity and quality and are poorly prepared to meet these challenges (10).

An in-depth study of the Iringa district of Tanzania, a poor rural area, showed that patients bypassed low quality facilities in favor of those offering high quality consultation and prescriptions, staffed by more knowledgeable physicians and better stocked with basic supplies (11).

In Ethiopia the low level of socio-economic development resulting in one of the low standard of living, poor environmental conditions and low level of social services has been the major causes for a poor health status of the people $(12,13)$.

Several studies conducted in Out Patient Departments of different hospitals in Ethiopia revealed client satisfaction level ranging from $22.0 \%$ in Gondar to $57.1 \%$ in Jimma $(14,16,17)$. Long waiting hours during registration, visiting of Doctors after registration, laboratory procedures and re-visiting of the Doctor for evaluation with laboratory results failure to obtain prescribed medications from the hospitals' pharmacies and difficulty to locate different sections were the frequently faced problems affecting utilization leading to dissatisfaction $(15,18)$.

This study would have an important input in assessing the level of clients' satisfaction on outpatient as well as inpatient health care services, identify the factors affecting the clients' satisfaction, and provide a recommendation on an improved health service delivery that will be helpful to fill research knowledge gaps which ultimately contributes to enhance quality of patient services in the hospital and improve the level of clients' satisfaction.

\section{METHODS AND SUBJECTS}

A cross sectional descriptive study was conducted to assess the perceived levels of clients' satisfaction with health services rendered at Jimma University Specialized Hospital, which is located $350 \mathrm{KM}$ Southwest of Addis Ababa. JUSH is a referral and teaching hospital running annual budget of Birr more than 20 million with bed capacity of over 450 and total staff exceeding 550.It provides services for approximately 9000 inpatient, 5000 accident and emergency cases and 80,000 outpatient attendants each year.

All clients visiting the hospital for health services from March 1/2010 to March 8/2010 were the source population. Sample size(n) was determined based on the assumption of $50 \%$ satisfaction level, Expected margin of error (d) of 0.05 and with $95 \%$ confidence level $\left(Z_{\alpha / 2}\right)$ and $10 \%$ contingency for non-response. The study population was selected using systematic random sampling technique. According to the data obtained from the Hospital the annual cases seen at OPD is estimated to be 80000 excluding accidents and emergencies and the annual 
admission rate is 9000 .Therefore the proportional sample size for inpatient was 40 and shared equally among Internal medicine, Surgery and Gynecology \&Obstetrics wards. For Outpatient services the sample size was 382 and divided among OPDs of the above mentioned Departments. As a result, 422 clients were involved in the study. Questionnaire was administered to every $5^{\text {th }}$ of Outpatient clients who received treatment and completed their visit and similar exit interview was administered to every other inpatient clients on their discharge date.

Structured questionnaire was developed in English and the interview was administered by medical interns who can speak Afan Oromo fluently, after orientation training on purpose of the study and proper administration of questioners was conducted for one day. The questionnaire was designed to obtain information on socio demographic characteristics of respondents and their satisfaction level with the different components of the Hospital's services which included the availability of drugs and supplies, information provision by the health workers, waiting time to get the services, courtesy and respect of the health workers, and cleanliness of waiting areas, toilets and wards of the hospital.

Data consistency and completeness was checked throughout the data collection, data entry and analysis. Data were coded and entered into computer using SPSS version 16.0 software. In the analysis of client satisfaction the very satisfied and very dissatisfied were categorized to satisfied and dissatisfied groups because the numbers of the respondents in the very satisfied and dissatisfied were small. Frequency distribution, percentages and Chi-square test were calculated for selected variables to check associations at 5\% level of significance. Prior to this study an official letter from the college of public health and medical sciences was written to the Hospital to conduct the study and verbal consent from the Medical director, and Head nurses was secured. Informed consent was also obtained from the clients after explaining the purpose of the study.
The following Operational definitions were used during the conduct of this study;

Patient waiting time: The interval between departure from the proceeding outpatient station and receiving service at the next outpatient station.

Outpatient station: The different part of outpatient department, registration station, weighing station, examination room laboratory, and dispensary etc...

Consultation time: The time spent discussing health matter with one's physician.

Satisfaction: Attaining one's need or desire.

Very satisfactory: Above one's expectation.

Satisfactory: Just one's expectation.

Dissatisfactory: Below one's expectation.

Very dissatisfactory: Fail to meet one's expectation usually leading to disappointment.

Assessment: Is the process by which the characteristics and needs of clients, groups or situations are evaluated or determined so that they can be addressed. The assessment forms the basis of a plan for service or actions.

Service: any activity undertaken to meet the social needs.

Quality: User based quality is defined as "fitness for use", which means the consumer's perception of quality. It is also defined as meeting the desires and expectations of customers"

\section{RESULTS}

A total of 422 clients were enrolled in the study and there was comparable gender distribution with slight male predominance $(51.7 \%)$ and $33.4 \%$ of the clients were between the age group of 25-34 years. Considerable number of clients $(41 \%)$ were not able to read and write, while, $304(72 \%)$ were married. Farmers account for $48.6 \%$ and 253 $(60 \%)$ of the clients were from the rural areas. Out of the total respondents, $54.7 \%$ were revisiting and $91.0 \%$ came because of illnesses. $344(81.5 \%)$ were clients themselves and the rest were close family members and others. Nearly three fifth of the clients $(57.8 \%)$ received the services free of charge. Concerning the ethnic composition of the clients, 306 (72.9) of them were Oromo, and 273 $(64.7 \%)$ were followers of Islam (Table 1). 
Table- 1: Socio-demographic characteristics of respondents JUSH March, 2010(n=422)

\begin{tabular}{|c|c|c|}
\hline \multicolumn{2}{|c|}{ Background characteristics } & \multirow{2}{*}{$\begin{array}{l}\text { No (\%) } \\
218(51.7)\end{array}$} \\
\hline Sex & Male & \\
\hline & Female & $204(48.3)$ \\
\hline \multirow[t]{4}{*}{ Age (in years) } & $15-24$ & $67(15.9)$ \\
\hline & $25-34$ & $141(33.4)$ \\
\hline & $35-44$ & $135(32.0)$ \\
\hline & $45+$ & $79(18.7)$ \\
\hline \multirow[t]{4}{*}{ Marital Status } & single & $80(19.0)$ \\
\hline & married & $304(72.0)$ \\
\hline & widowed & $14(3.3)$ \\
\hline & divorced & $24(5.7)$ \\
\hline \multirow[t]{4}{*}{ Educational Status } & Illiterate(cannot read or write) & $173(41.0)$ \\
\hline & $1-6$ & $112(26.5)$ \\
\hline & $7-12$ & $89(21.1)$ \\
\hline & Diploma \&above & $48(11.4)$ \\
\hline \multirow[t]{6}{*}{ Occupational status } & Farmer & $205(48.6)$ \\
\hline & Merchant & $78(18.5)$ \\
\hline & Government employ & $48(11.4)$ \\
\hline & No occupation & $15(3.6)$ \\
\hline & Student & $49(11.6)$ \\
\hline & Others $(\mathrm{C}$ & $27(6.4)$ \\
\hline \multirow[t]{2}{*}{ Address } & Rural & $253(60.0)$ \\
\hline & Urban & $169(40.0)$ \\
\hline \multirow[t]{2}{*}{ Payment status } & Free & $244(57.8)$ \\
\hline & Paying & $178(42.2)$ \\
\hline \multirow[t]{3}{*}{ Reason for visit } & Illness & $384(91.0)$ \\
\hline & Family planning & $30(7.1)$ \\
\hline & Others ${ }^{\alpha}$ & $8(1.9)$ \\
\hline \multirow[t]{2}{*}{ Frequency of visit } & New visit & $191(45.3)$ \\
\hline & Repeat visit & $231(54.7)$ \\
\hline \multirow[t]{4}{*}{ Religion } & Muslim & $273(64.7)$ \\
\hline & Orthodox & $105(24.9)$ \\
\hline & Protestant & $43(10.2)$ \\
\hline & Others & $1(0.2)$ \\
\hline \multirow[t]{5}{*}{ Ethnicity } & Oromo & $306(72.9)$ \\
\hline & Amhara & $69(16.4)$ \\
\hline & Keffa & $20(5.3)$ \\
\hline & Dawro & $15(3.5)$ \\
\hline & others ${ }^{\beta}$ & $10(2.4)$ \\
\hline
\end{tabular}

(C)=housewife, employee in private sector, no occupation $\alpha=$ immunization, injection, dressing

$\beta=$ Gurage, Yem, Welaita, Silte, Agnuak. Etc 
Among the Outpatient clients, the way the doctor examined the clients was the aspect where satisfaction was rated highest $349(91.36 \%)$ and satisfaction was rated lowest $(53.1 \%)$ with the time spent to see a doctor. Out of 40 admitted patients included in the study 22 (55\%) were satisfied with the food service of the hospital and contrary to this, $24(60 \%)$ were dissatisfied with the visiting hours of the hospital. Nearly two fifth of the respondents $(39 \%)$ responded they were not satisfied with the information provision about the hospital services and the flow. Out of 344 laboratory orders $178(51.74 \%)$ got all the ordered procedures and of the 247 radiology requests $184(74.50 \%)$ were able to get the requested procedure in the Hospital. While, $88.2 \%$ of the total clients got a prescription paper for drugs and supplies, only $33.3 \%$, got all the prescribed drugs. Over one third $(37.0 \%)$ of the respondents reported dissatisfaction with the overall waiting time to get the hospital services, while $23.5 \%$ of the clients were dissatisfied with the lack of drugs and supplies in the hospital (Table 2).

Table- 2 Level of satisfaction of clients with the different components of health care services JUSH, March, 2010(n=422).

\begin{tabular}{llllll}
\hline \hline Characteristics & $\begin{array}{l}\text { V. sat } \\
(\mathbf{\% )}\end{array}$ & $\begin{array}{l}\text { Sat. } \\
\mathbf{( \% )}\end{array}$ & $\begin{array}{l}\text { Neut. } \\
\mathbf{( \% )}\end{array}$ & $\begin{array}{l}\text { Dissat } \\
\mathbf{( \% )}\end{array}$ & $\begin{array}{l}\text { V.dissat } \\
\mathbf{( \% )}\end{array}$ \\
\hline \hline Information provision by health workers & 12.2 & 51.7 & 18.7 & 13.0 & 4.5 \\
Time spent to see a Dr & 5.9 & 47.2 & 12.3 & 32.4 & 2.4 \\
Courtesy and respect & 11.8 & 64 & 11.6 & 10.9 & 1.7 \\
Privacy & 13.7 & 41.9 & 13.3 & 23.9 & 7.1 \\
Access to latrines & 10.7 & 58.5 & 10.2 & 17.3 & 3.3 \\
Cleanliness of latrines & 7.8 & 58.8 & 9.5 & 19.7 & 4.3 \\
Cleanness of wards & 15.0 & 30.0 & 5.0 & 50 & 0.0 \\
Cleanness of bedding & 5.0 & 42.5 & 5.0 & 45 & 2.5 \\
Queue process to see a Doctor & 6.9 & 48.6 & 11.8 & 32.0 & 0.7 \\
The way the Doctor examined & 28.0 & 54.7 & 5.2 & 11.4 & 0.7 \\
Confidentiality & 8.1 & 53.8 & 20.9 & 14.0 & 3.3 \\
Availability of drugs & 19.0 & 36.0 & 13.3 & 20.4 & 3.1 \\
Food & 5.0 & 50.0 & 25.0 & 15.0 & 5.0 \\
Overall waiting time & 3.1 & 44.5 & 15.4 & 36.5 & 0.5 \\
Visiting hours & 2.5 & 37.5 & 10.0 & 27.5 & 22.5 \\
Way questions \&queries dealt by staff & 5.0 & 37.5 & 10.0 & 47.5 & 0.0 \\
Overall level of satisfaction & 6.2 & 70.9 & 7.8 & 15.2 & 0.0 \\
\hline \hline
\end{tabular}

v.sat $=$ very satisfied sat $=$ satisfied neut $=$ neutral dissat $=$ dissatisfied

v.dissat $=$ very dissatisfied

There was statistically significant association between client's satisfaction and their age $(p=0.034)$, their educational status $(p=0.003)$, occupational status of the respondents, $(\mathrm{p}=0.002)$, address of the respondents $(\mathrm{p}=0.000)$, payment scheme of the respondents $(\mathrm{p}=0.000)$ and waiting time to see a doctor $(\mathrm{p}=0.000)($ Tables $3,4,5)$. 
Table-3 Comparison of overall level of clients' satisfaction with health services rendered at Jimma University Specialized Hospital by selected socio - demographic characteristics, March 2010.

\begin{tabular}{|c|c|c|c|c|}
\hline Characteristics & & $\begin{array}{l}\text { Satisfied } \\
\text { No (\%) } \\
\end{array}$ & $\begin{array}{l}\text { Dissatisfied } \\
\text { No (\%) } \\
\end{array}$ & p-value \\
\hline \multirow[t]{2}{*}{$\operatorname{sex}$} & Male & $161(82.1))$ & $35(17.90)$ & 0.451 \\
\hline & Female & $164(85.00))$ & $29(15.00)$ & \\
\hline \multirow[t]{4}{*}{ Age in years } & $15-24$ & $39(70.90)$ & $16(29.10)$ & \\
\hline & $25-34$ & $111(85.4)$ & $19(14.50)$ & 0.034 \\
\hline & $35-44$ & $107((83.60)$ & $21(16.70)$ & \\
\hline & $45+$ & $68(89.50)$ & $8(10.50)$ & \\
\hline \multirow[t]{4}{*}{ Educational status } & Illiterate & $154(90.60)$ & $16(9.40)$ & \\
\hline & $1-6$ & $84(82.40)$ & $18(17.60)$ & \\
\hline & $7-12$ & $58(72.50)$ & $22(27.50)$ & 0.003 \\
\hline & Diploma \&above & $29(78.40)$ & $8(21.60)$ & \\
\hline \multirow[t]{2}{*}{ Address } & Urban & $109(73.20)$ & $40(26.80)$. & \\
\hline & Rural & $216(90.00)$ & $24(10.00)$ & 0.000 \\
\hline \multirow[t]{2}{*}{ Payment status } & Paying & $113(69.30)$ & $50(30.70)$ & \\
\hline & Free & $212(93.80)$ & $14(6.20)$ & 0.000 \\
\hline \multirow[t]{5}{*}{ Occupation } & Farmer & $180(90.00)$ & $20(10.00)$ & \\
\hline & Merchant & $51(71.80)$ & $20(28.20)$ & \\
\hline & Governmental & $34(75.60)$ & $11(24.40)$ & \\
\hline & $\begin{array}{l}\text { employee } \\
\text { student }\end{array}$ & $28(75.70)$ & $9(24.30)$ & 0.002 \\
\hline & Others & $20(83.30)$ & $4(16.70)$ & \\
\hline \multirow[t]{4}{*}{ Status of respondents } & Patients & $258(80.60)$ & $62(19.40)$ & \\
\hline & FP and & $18(100)$ & $0(0.00)$ & \\
\hline & Vaccination users & & & 0.003 \\
\hline & Family members & $49(96.10)$ & $2(3.90)$ & \\
\hline
\end{tabular}

Table- 4: Clients' satisfaction on availability of drugs by selected sociodemographic characteristics, 2010.

\begin{tabular}{|c|c|c|c|c|}
\hline Characteristics & & $\begin{array}{l}\text { Satisfied } \\
\text { N0 (\%) } \\
\end{array}$ & $\begin{array}{c}\text { Dissatisfied } \\
\text { N0 (\%) }\end{array}$ & p-value \\
\hline \multirow[t]{2}{*}{ Sex } & Male & $115(67.30)$ & $56(32.70)$ & \\
\hline & Female & $118(73.30)$ & $43(26.70)$ & 0.229 \\
\hline \multirow[t]{4}{*}{ Age in years } & $15-24$ & $31(67.40)$ & $15(32.60)$ & \\
\hline & $25-34$ & $70(65.40)$ & $37(34.60)$ & \\
\hline & $35-44$ & $80(74.80)$ & $27(25.20)$ & 0.467 \\
\hline & $45+$ & $52(72.20)$ & $20(27.80)$ & \\
\hline \multirow{4}{*}{$\begin{array}{l}\text { Educational } \\
\text { status }\end{array}$} & Illiterate & $113(76.90)$ & $34(23.10)$ & \\
\hline & $1-6$ & $60(74.10)$ & $21(25.90)$ & \\
\hline & $7-12$ & $38(56.70)$ & $29(43.30)$ & .009 \\
\hline & Diploma \&above & $22(59.50)$ & $15(40.10)$ & \\
\hline \multirow[t]{2}{*}{ Address } & Urban & $75(61.00)$ & $48(39.00)$ & \\
\hline & Rural & $158(75.60)$ & $51(24.40)$ & 0.005 \\
\hline \multirow[t]{2}{*}{ Payment status } & Paying & $76(52.80)$ & $68(47.20)$ & \\
\hline & Free & $157(83.50)$ & $31(16.50)$ & 0.000 \\
\hline \multirow{2}{*}{$\begin{array}{l}\text { Frequency of } \\
\text { visit }\end{array}$} & New & $108(78.80)$ & $29(21.20)$ & \\
\hline & Repeat & $125(64.10)$ & $70(35.90)$ & 0.004 \\
\hline
\end{tabular}




\section{DISCUSSION}

This study has revealed that the overall satisfaction level of the clients with the services rendered at JUSH was $77.0 \%$. and this is higher than reports from other studies conducted in Jimma Hospital and in a Mozambique Hospital which showed $57.1 \%$ and $55 \%$, respectively (19, $20)$. This level of satisfaction is also higher when compared to studies conducted in the hospitals of the Amhara region which showed satisfaction level of $22.0 \%$ to $50 \%(15,16)$. Likewise, a report from Tigray zonal hospitals revealed satisfaction level of $43.60 \%$ (17). The difference might be attributed to the fact that this study was conducted in a specialized teaching hospital where there are relatively adequate number of health professionals and better diagnostic facilities. In addition, study time and design might have also contributed. The present study was facility based and that of Gondar was a community based. Thus, this study should be interpreted with caution as it may tend to exaggerate social desirability bias and subjected to Hawthorne effect (courtesy bias).
The study has revealed that lack of drugs and supplies in the hospital pharmacies was the major problem, where about $70 \%$ of the clients with prescription paper for drugs did not get some or all of the ordered drugs from the Hospital's Pharmacy. This finding is similar with that of the study conducted in Jimma hospital earlier, where $63.7 \%$ of the clients lacked drugs from the hospital's pharmacies. It is also a comparable finding with that of study in Tigray Zonal hospitals which reported about $61 \%$ of those clients with prescription paper for drugs did not get the ordered drugs from the hospital pharmacies (17). However, our finding is higher than that of the study conducted in the hospitals of the Amhara region where about $1 / 3^{\text {rd }}$ of the clients did not get the prescribed drugs (16).

Failure to obtain the prescribed drugs from the hospital's pharmacy is in line with a report from a study conducted in Manica, Mozambique where it was found to be the most complaint associated with lower satisfaction (20). Another study conducted in South Africa also revealed that access to drugs was one of the most suggested priorities for improvement of public health services (21).

Table- 5 Comparison of client satisfaction with the overall waiting time to get the outpatient services by selected socio - demographic characteristics at JUSH March, 2010.

\begin{tabular}{|c|c|c|c|c|}
\hline \multicolumn{2}{|l|}{ Characteristics } & Satisfied & Dissatisfied & p-value \\
\hline \multirow[t]{2}{*}{ Walking time (hrs) } & $<1$ hour & $\begin{array}{l}\text { No (\%) } \\
47(73.30)\end{array}$ & $\begin{array}{l}\text { No (\%) } \\
18(27.70)\end{array}$ & \multirow{4}{*}{0.000} \\
\hline & $1-2$ hour & $108(86.40)$ & $17(13.60)$ & \\
\hline \multirow{5}{*}{ Time to see Drs (hrs) } & $2-6$ hours & $90(94.7)$ & $5(5.30)$ & \\
\hline & $>6$ hours & $80(76.9)$ & $24(23.1)$ & \\
\hline & $<1 \mathrm{hr}$ & $70(95.90)$ & $3(4.100$ & \multirow{3}{*}{0.000} \\
\hline & $1-2$ hours & $189(91.70)$ & $17(8.30)$ & \\
\hline & $>2$ hours & $66(60.00)$ & $44(40.00)$ & \\
\hline \multirow{3}{*}{$\begin{array}{l}\text { Giving lab } \\
\text { specimen(hrs) }\end{array}$} & $<1 \mathrm{hr}$ & $129(92.10)$ & $11(7.90)$ & \multirow{3}{*}{0.000} \\
\hline & $1-2$ hours & $80(80)$ & $20(20)$ & \\
\hline & $>2$ hours & $50(62.5)$ & $30(37.5)$ & \\
\hline \multirow{3}{*}{$\begin{array}{l}\text { Waiting time to see the } \\
\text { Dr after receiving the } \\
\text { lab result }\end{array}$} & $<1 \mathrm{hr}$ & $71(91.00)$ & $7(9.00)$ & \multirow{3}{*}{0.000} \\
\hline & $1-2$ hours & $147(91.90)$ & $13(8.10)$ & \\
\hline & $>2$ hours & $49(53.8)$ & $42(46.2)$ & \\
\hline
\end{tabular}


As it has been indicated in the resulted, dissatisfaction because of lack of drugs in the Hospital's pharmacies was statistically significant with payment status ( $\mathrm{p}=0.000$ ), Where about $39 \%$ of the clients from urban areas and about $47 \%$ of the paying clients were dissatisfied because of it. Many studies have also indicated that patients equate availability of drugs with high quality services (7).

Twenty percent of the clients in the present study were dissatisfied with the provision of information about the hospital services and their health problems. This is quite a low dissatisfaction rate when compared to the study conducted in Tigray zonal hospitals with $46.7 \%$ dissatisfaction rate (17). The reason for the big difference could be due to the difference in the number and type of health care providers in those mentioned service delivery places and the variety of activities they run in their respective areas.

A study conducted in South Africa revealed lack of communication and relevant messages to patients were identified as an important issue impacting on quality thus affecting client satisfaction (21). Highest satisfaction rate $(82.7 \%)$ in this study may be attributed the way the doctor examined the clients. This high result could be expected in the study area hospital as it is a teaching center so that health professionals at different level are expected to demonstrate the standard way of patient examination. In contrary the lack of respect and courtesy were among the major reasons for dissatisfaction in Gondar study (15).

In a study conducted in South Africa, the comments made about the poor quality of the relationships with the practitioner included: lack of empathy, mistreatment, lack of respect and lack of communication (21).

As to this study, $37.2 \%$ of the clients were dissatisfied by the overall waiting time to get the services. This is higher than the finding reported earlier in Jimma hospital which showed $20.4 \%$ of the clients have reported long waiting time (19).This higher dissatisfaction rate with waiting time could be attributed to the increased number of clients. However, the dissatisfaction rate with waiting time to receive the services in the study area is lower compared to the waiting time in the study in Tigray Zonal hospitals where $43.2 \%$ dissatisfaction rate was reported (17).
This better finding could partially be due to the ongoing changes in the study area hospital because of the newly introduced reform, where an improvement in the service delivery process and staff attitudinal change might have resulted. Analysis of overall satisfaction by sociodemographic characteristics showed that educational status, and age were associated with satisfaction, where respondents who are illiterate, and the older age group were more satisfied as compared to those who have tertiary education (diploma and above) and the younger age groups respectively. This is in agreement with the study in Jimma Hospital in which satisfaction score was directly related to the age but had an in inverse relation to educational status, high education associated with low satisfaction score. It is also similar with a study conducted in Trinidad and Tobago which showed the percentage of satisfied clients decreased with increased educational status, but increased with increasing age (22). The reason could be due to high expectation by those who are more educated than the illiterate (could be true for those who came from rural and for farmers) and confidence in medical care system and satisfaction in life in general by the older age groups.

In conclusion, the hospital management needs to understand the extent of the problem with drugs and supplies and plan to look for different mechanisms to keep adequate stock of essential drugs and supplies, fulfill human resource and standard medical equipment, establish an information desk at a convenient corner of the hospitals which would particularly be helpful for the majority of the clients who are illiterates, and avoid long waiting time and lack of privacy.

\section{ACKNOWLEDGEMENTS}

The authors are grateful to the student research project of Jimma University for its support. We would like to acknowledge the study participants for their genuine participation and information. 


\section{REFERENCES}

1. Mathew S. and Beth E. Guide to Assessing Client Satisfaction. Durban, (South Africa): Health system Trust; January 2001.

2. Health care Commission-North West London Hospitals NHS Trust. Outpatient survey report, 2004/2005.

3. Margaret S. West away, Paul Rheeder, Daniel G. Vanzyl, John R. Seager. Interpersonal and organizational dimensions of patient satisfaction. Journal for Quality in Health care, 2003; 15(4): 337-44.

4. Larsen DE, Rootman R. Physician's role performance and patient satisfaction. Soc Sci med, 1976; 10:29-32.

5. Donabedian A. The quality of care. How can it be assessed? J Am Med Assoc, 1988; 260:1743-48.

6. James AW. Hospital management in the tropics and subtropics; 1990.

7. Margaret Brawley. The client perspective, what is quality health care service; 2000.

8. Surjit SW. Customer satisfaction and health care delivery system: the internet Journal of Nuclear M. 2002; 1(1): ISSN 1539-4638. Available from URL:http://ispub.com/ostia/index.

9. Jorge MA; Herga P, Ahmed A. Client satisfaction and quality of health care in rural Bangladesh. Bulletin of the WHO 2001; 79: 512-517.

10. Peter A. Berman, A decade of health sector reform in developing countries, 2000.

11. Batchelor C, Owens DJ, Read $M$ and Bloor M. Patient Satisfaction Studies, Methodologies, Management and Consumer evaluation. An international Journal of Health Care Quality Assurance, 1994;7(7): 22-30.
12. MoH. Health and Health related indicators, Ministry Of Health, 2001 E.C

13. Ministry of Health. Health Sector Strategy. Ministry Of Health, Addis Ababa, 2002/2003.

14. Health and Health related indicators, Ministry Of Health, 2002/2003.

15. Dagnew M, D Zakus D. Community perception on OPD performance of a teaching hospital in Gondar town, Ethiopia. Ethiop Med J Dev, 1997, 35; $153-160$.

16. Mitike G, Mekonnen A, Osman M, Satisfaction on outpatient services in hospitals of the Amhara region. Ethiop Med J, 2002; 40; 387 - 395.

17. Girmay A. Assessment of clients' satisfaction with outpatient services in Tigray Zonal Hospitals. [Online]. 2006; Available from: URL:http://etd.edu.et/

18. Birna A. The quality of hospital services in eastern Ethiopia: Patient's perspective. Ethiop J Health Dev, 2006; 20(3): 199200.

19. Olijera L, Gebresilasses S. Satisfaction with outpatient health services at Jimma hospital, South West Ethiopia. Ethiop $J$ Health Dev, 2001;15(3):179-184.

20. Newman D, Gloyd S, Nyangez MJ, Machoro F. Satisfaction with outpatient health care service in Manica province, Mozambique. Health policy and planning, 1998; 15(3): $179-184$.

21. Gary Morris, Improving quality of services, South Africa, 1998.

22. Singl H, Haqq ED, Mustapha N. Patient's perception and satisfaction with health care facilities in Trinidad and Tobago. Bull WHO, 1999; 77:356-358. 